\title{
$\frac{\operatorname{Pol} 1001.40}{\text { PR D C D }}$
}

\section{PRS

دور الرقابة البيئية في استدامة الموارد الطبيعية المتمثلة بـ (الماء والهواء والتربة والمياه الجوفية) للحد من التلوث دراسة حالة معالجة الماء المصاحب لإستخراج النفط الخام

$$
\begin{aligned}
& \text { منى فؤاد عبد الهادي } \\
& \text { ديو ان الرقابة المالية الاتحادي }
\end{aligned}
$$

Corresponding Author E-mail: mounafhade@gmail.com

الملخص: يسلط البحث الضوء على اهمية الموارد الطبيعية المتمثلة بـ (الماء و الهواء والتربة والمياه الجوفية) واهمية استدامتها التي ترتبط مبانرةً باستدامة الحياة الصحية للكائنات الحية على الارض رمع بيان الدور الذي يلعبهُ الاستخدام البشري لها وانعكاسهُ على مدى صالحية هذهِ الموارد واستدامتها للاجيال القادمة لذا كان من الضروري ايجاد الوسائل التي من خلالها يتم الحفاظ على استدامة الموارد الطبيعية وكانت الرقابة البيئية هي

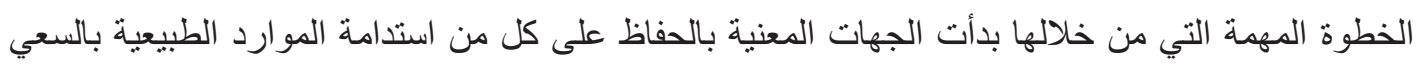
لتفعيل دور ها ليشمل كافة مجالات الحياة الني من شأنها الحفاظ على هذه الموارد وتحديد كل مامن شأنه بأنه استهلاكهاو نفاذها وكان التلوث احد اهم المصادر المؤثرة على استدامة الموارد الطبيعية. تعد شركة نفط الوسط شركة عامة (عر اقية الجنسية) كأحدى مصادر التلوث المهمة فمن خلال قيامها بنشاطها الاستخر اجي للنفط الخام الذي يكون بحقن المكمن (البئر) بكمية من الماء يختلف بحسب قوة المكمن ليخرج ذلك الماء مصاحباً للنفط المستخرج من البئر الذي يجمع على شكل مصطحات مائية ملوثة غير صالحة لاستخدام الكائنات الحية، مع عدم امتلاك هذه الشركة ونظير اتها معالجات حقيقية شاملة وقادرة على مو اجهة هذهِ البرك المائية ، فمن خلال استخدام قائمة الفحص التي وزعت على عدد من موظفي هذهِ الثركة وكذلك

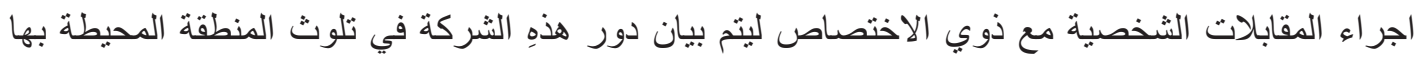

$$
\text { و عرض أجر اءات السلامة البيئية المتبعة لديها. }
$$
و هذا ما تم التطرق اليه في اجزاء البحث من خلال استتناجاته التي تم التوصل إليها من خلال الدر اسة النظرية و التطبيق العملي لموضوع البحث المتمثل بقائمة الفحص. 


\section{Astract:}

This work shows the importance of the natural resources represented by (water, air, soil and groundwater) and the importance of their sustainability that are directly related to the healthy life of living organisms on the ground with an indication of the role that the impact of human use of such resources and on the extent to which these resources are viable and sustainable for future generations. Therefore, it is necessary to find the means by which the sustainability of natural resources is maintained.

Environmental monitoring is a vital tool by which stakeholders have started to maintain the sustainability of natural resources and preserve environment by activating their roles and expanding them to include all aspects of life that would preserve these resources and determine everything that would be consumed and enforced Pollution was one of the most important sources affecting the sustainability of natural resources.

Midlands Oil Company as one of the important sources of pollution. Through its extractive activity of crude oil, which is injecting the reservoir (the well) with a quantity of water that varies according to the strength of the reservoir that water comes out of the oil extracted from the well, which collects in the form of polluted water bodies. Not valid for the use of living organisms, with this company and its counterparts not having comprehensive real treatments capable of confronting these water pools, by using the checklist distributed to a number of the employees of this company as well as conducting personal interviews with specialists to clarify the role of this company in pollution of the region Surrounding and view their environmental safety procedures. This issuer posed in this Research have been addressed and presented recommendation to in the light of con collusions of the theoretical study and practical application of the research being the checklist mentioned. 
للرقابة البيئية دور اً فعالاً في استدامة الموارد الطبيعية المتمثلة بـ (الماء و الهو اءو التربة والمياه الجوفية) وذلك لسعى الرقابة البيئية للحفاظ على الثروة الطبيعية والحد من زيادة معدلات التلوث التي نجمت عن زيادة معدلات الانتاج الصناعي والغذائي وعمليات انتاج النفط والغاز التي جعلت انظار العالم تتجه نحو ايجاد الحلول لتوفير فرص متساوية واكثر عدالة لجميع الافر اد في التمتع بالموارد الطبيعية، وفي ضوء موضوع

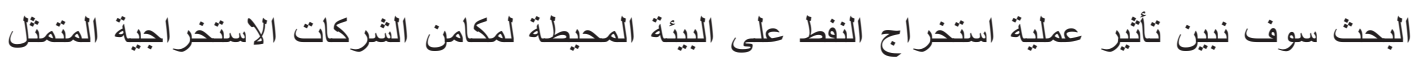
بشركة نفط الوسط شركة عامة (عر اقية الجنسية) وما تخلفه عملية الاستخر اج من تلوث يؤثر على الموارد

اذ ان وجود نظام رقابي فعال يستتد الى اسس ومعايير رصينة مستمدة من انظمة وقو انين مختلفة تفرضها الدولة على نشاطات الثركات الاستخر اجية التي تؤثر مراحل عملها على البيئة بهدف مراقبة مصائل مصادر

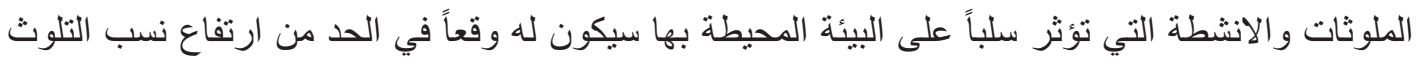
البيئي، ويبين الجانب العملي المتمثل بقائمة الفحص الاستفسارات التي وجهت للشركة الاستخر اجية اعلاه من خلال الاجابة على تساؤلات القائمة يتم تحديث برنامج التدقيق البيئي المعد في ديوان الرقابة المالية الاتحادي الذي ير اقب به على عمل الثركات الاستخر اجية للحد من تأثير نشاطها ومخلفاته المتمثلة بالنفايات على تلوث البيئة المحيطة بها. 2- 2 الجانب النظري: 1-2

يتطلب استخر اج النفط الخام حقن الآبار بالماء في ادنى نقطة لمكمن البئر النفطي اذ ان ضخ الماء يؤدي لرفع الضغط داخل البئر وبالتالي استمرار تدفق النفط من الآبار الاخرى التي حوله اذ يقابل كل برميل نفط مستخرج كمية من الماء تزداد وتنخفض حسب قوة المكمن وتخرج هذه الكمبة من البئر مصاحبة للنفط الخام



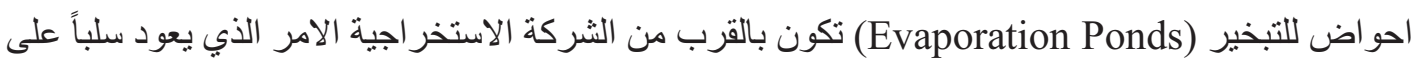
البيئة وصحة الكائنات الحية اضافة لاحداث مشاكل فنية نؤدي بدور ها الى تقليص العمر الانتاجي للبئر الامر برد

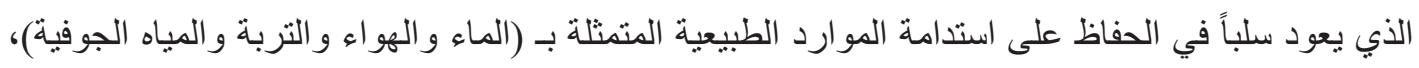
لذا نطلب اليوم نوفير انظمة رقابية تعمل على ايجاد الحلول لمعالجة هذه المياه وتأهيلها لتكون صالحة للاستخدام وحقنها في الابار النفطية من جديد بهدف الحفاظ على الثروة المائية للبلاد.

2-2 1- اعطاء دور للرقابة البيئة على مستوى البلاد لمر اقبة منطلبات استخر اج النفط الخام وغير ها من الصناعات من خلال تثكيل هيئآت رقابية بيئية. 
2- الاهتمام بالمو ارد الطبيعية المتمنلة بـ (الماء و الهو اء و التربة و المياه الجوفية) وجعل استدامتها من اولويات

$$
\text { الحكومات المتعاقبة. }
$$

3- الحد من التلوث البيئي وصولاً لأستدامة الموارد الطبيعية المتمثلة بـ (الماء والهواء والتربة والمياه

$$
\text { (الجوفية). }
$$

4- الزام الثركات النفطية بتنفيذ معايير الرقابة البيئية في عملها من خلال هيئآت الرقابة البيئية المتواجدة في مقر اتها للتأكد من مدى تنفيذ تلك المعايير.

3-2 1 اهداف البحمث: 1- ايجاد علاقة بين دور الرقابة البيئية واستدامة الموارد الطبيعية المتمثلة بـ (الماء و الهواء والتربة و المباه الجوفية) و اعتبار ها ثروة لابد من الحفاظ عليها.

2- الحد من التلوث البيئي وذلك بنطبيق شركات الاستخر اج النفطي لمعايير الرقابة البيئية. 3- بيان الاثر السلبي للماء المصاحب لاستخراج النفط الخام من الآبار النفطية المتمثلة بالمصطحات المائية

$$
\text { الملوثة (البرك الملوثة). }
$$

\section{4-2 فرضية البحث:- يقوم البحث على فرضيتين:}

1- للرقابة البيئية دور اً فعالاً في الحد من التلوث الذي تتعرض له البيئة المتمثلة بـ (الماء و الهواء و التربة و المياه الجوفية) جر اء قيام الثركات النفطية الاستخر اجية باستخر اج النفط الخام .

2- للمسطحات المائية الملوثة الناتجة عن عملية استخر اج النفط الخام اثراً سلبياً على البيئة المحيطة لمكمن الابار النفطية.

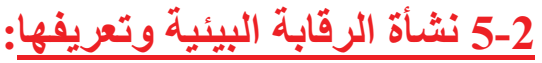

كثرت في الآونة الاخيرة الدراسات و الابحاث حول ايجاد السبل الكفيلة للحد من مشكلة تفاقم ظاهرة التلوث البيئي الذي يتعرض لله العالم بصورة عامة والعراق بصورة خاصة اضافة الى شحة المياه التي يعاني منها

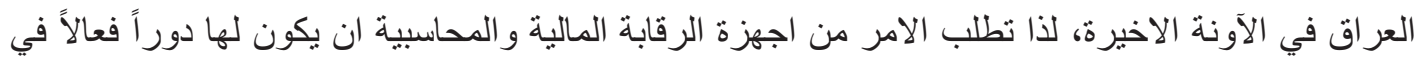

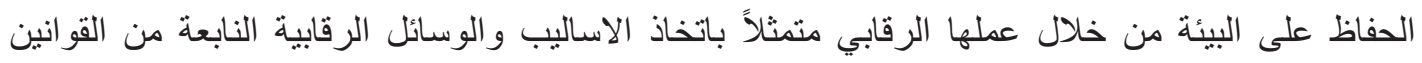
و التعليمات النافذة سعياً منها للحد من التلوث البيئي واستناداً لمجال بحثنا سوف نتكلم عن دور الرقابة البيئية

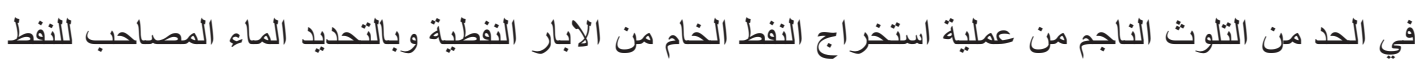
الخام المستخرج و انعكاسه على استدامة الموار الطبيعية المتمثلة بـ (الماء و الهو اء و التربة و المياه الجوفية) 
اذ تقوم الرقابة البيئية بجمع وتقييم البيانات وتوفير ها بشكل تقارير تساعد متخذب القرار على حل المشكلات

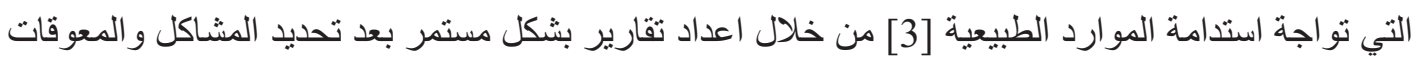
التي تحد من استدامة الموارد الطبيعية التي يعرضها التقرير ويقدم لاصحاب القرار على ان يكون دور الرقابة البيئية مستمر لغاية إيجاد الحلول المناسبة لها و العمل على عدم تكر ار ها مستقبلاً [4]. وقد عرفت الرقابة البيئية على انها" فحص انتقادي دوري منظم موثق وموضوعي لأنشطة الوحدة الأقتصادية

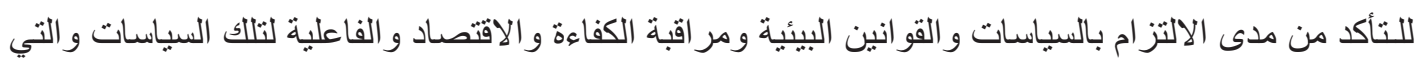
تتم عن طريق جهة مستقلة ومحايدة عن الوحدة الاقتصادية والتي تقوم باعداد تقرير بيئي يرفع لاطر اف داخلية وخارجية تساعدها في ترشيد قرار اتها نحو البيئة " [5].

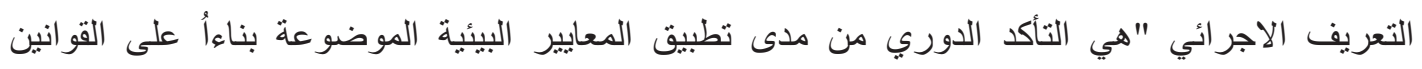



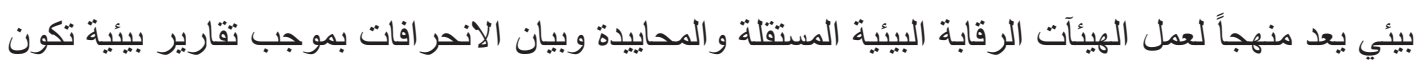
عوناً لمتخذي القرار ات في ايجاد الحلول لهاو العمل على عدم تكر ار ها مستقبلاً".

انواع الرقابة البيئية: - مابة ان الرقابة البيئية لاتبتعد كثثراً عن الرقابة المالية المعتمدة من الاجهزة العليا للرقابة المالية والمحاسبية وهي

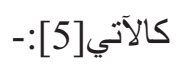

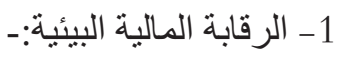

بيين هذا النوع من الرقابة انه على الجهات الخاضعة للرقابة الافصاح عن انشطتها البيئية وبيان مدى اثرها

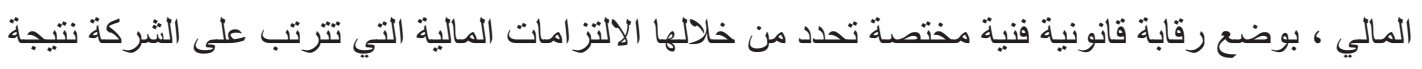
قبامها بعملها الذي يعود بالضرر على البيئة من خلال تحديد التكاليف المرتبطة بالضرر البيئي ومدى سلامة فئه

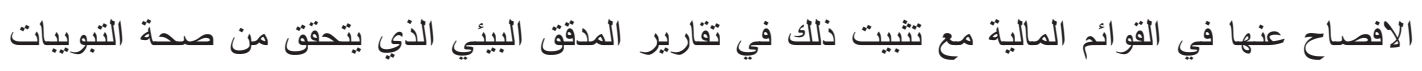
ومعالجة المصروفات والاصول ذات العلاقة بالانشطة المؤثرة على البيئة مع التحقق من المتحصلات نتيجة

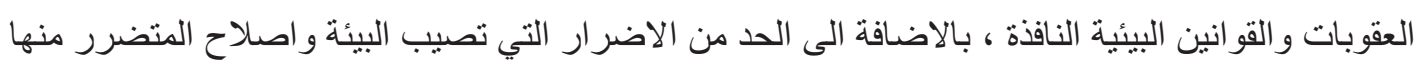

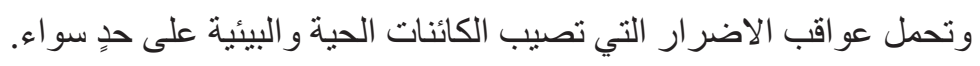

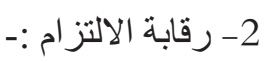

تعني التحقق من مدى الالتز ام بالقو انين و التعليمات و الانظمة النافذة عند تنفيذ انشطة وعمليات المشروع سو اءً

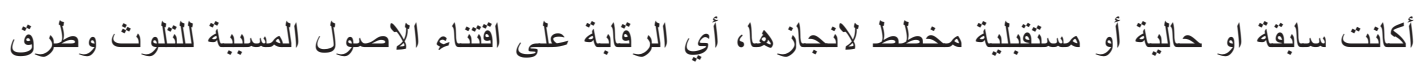

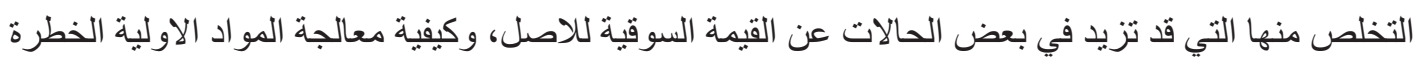


الداخلة في انشطة الثركة والنفايات بدءاً من اقتنائها الى التخلص منها والتحقق من وجود انظمة للسلامة البيئية تعمل على الحد من ارتفاع نسب التلوث و التحقق من ككون المنتج النهائي مطابق للمتطلبات البيئية .

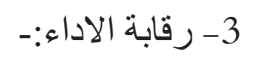

هي فحص مستقل لكفاءة وفاعلية المشاريع و البر امج الحكومية والاخذ بنظر الاعتبار الاقتصادية في تنفيذها شرط لتحقيق الاهداف [2] كما انها تهدف الى التحقق من اداء الجهة الخاضعة للرقابة لمؤشرات الاداء ذات الت التهاء الصلة بالبيئة وان الانشطة تتم وفق عناصر الاداء بكفاءة وفاعلية واقتصادية همع الأخذ بنظر الاعتبار العائد الناتج من تحقيق تلك المؤشرات بوجود نظام رقابي فعال منفعته تفوق تكلفة هذهِ المؤشر ات من خلال ضبط تكلفة نظام الرقابة وزيادة العائد من جر اء تطبيق هذا النظام [2 ،6 ،783

3- معايل الجودة الليئية. قد يكون الاساس الذي يعتمد علية في وضع معايير الجودة البيئية ليس واحداً لكل الثركات او لأي جهة طالبة لتحقيق اعلى جودة بيئية لمخرجاتها او النفايات المتحققة من انتاج تللك المنتجات التي قد تخضع لمعايير محلية او عالمية لذا يجب على الجهات الخاضعة للرقابة البيئية ان تعمل على تبني معايير الجودة البيئية الخاصة بها

$$
\text { لضمان ديمومتها في السوق [9] }
$$

ان معايير الجودة البيئية تضم سلسلة من معايير الجودة والمواصفات القياسية العالمية ومنها ذات العلاقة بموضوع البحث وهي معايير الادارة البيئية (ISO 14000) والصادرة سنة/ 1996، والتي عرفت بـأنهائ "مو اصفات موثوقة تستدعي من المنظمة المساهمة في الحفاظ على استخدام المواد الاولية وانتاج ومعالجة

$$
\text { وتصريف الفضلات الخطرة" [10، 11]. }
$$

التعريف الأجر ائي للجودة هي "وضع معيار ليس الهدف منهُ تقديم منتج مطابق لتطلعات المستهلك الحالية فقط بل يجب ان يكون المنتج اي المخرج النهائي صديقاً للبيئة فتطلعات المستهلك لاتنفي الحفاظ على صحة البيئة المستقبلية".

كما ان اهداف الجودة تتلخص بـما يلي [12 ،13]: 1- مساعدة المنظمات على اقامة نظام داخلي للادارة البيئية يضمن حسن التعامل مع القضايا البيئية. 2- مساعدة المنظمات على وضع الاهداف و السياسات الخاصة بها في مجال البيئة. 3- التزام المنظمات بالإعلان عن سياستها البيئية وبشروط السلامة امام السلطات الرقابية و الزبائن والرأي العام. 4- تشجيع المنظمات في سعيها للحصول على شهادات المطابقة من الجهات المختصة بهذا الثشإن. 
وقد قُسمت سلسلة معايير الادارة البيئية (14000 1SO) الى عدة مواصفات اخذ منها ماهو ذي علاقة بموضوع البحث هي (مواصفات نظام ادارة البيئة (14001)، مواصفات التدقيق البيئي (14002)، مو اصفات الملصق البيئي (14003)، مواصفات تقييم دورة الحياة (14004)، مواصفة مصطلحات الادارة البيئية

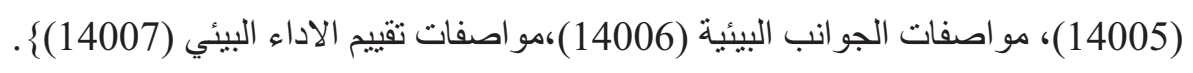

\section{1-3 القوانين والتشريعات العر اقية البيائة:}

يعد العراق من احد الدول التي تسعى للحفاظ على البيئة من التلوث جراء عمليات استخر اج النفط الخام من

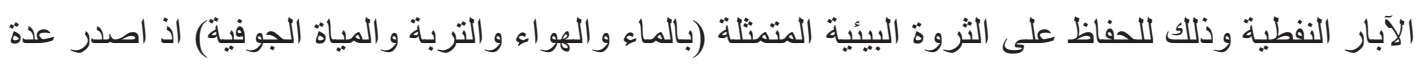
قو انين وتشريعات بيئية وكان اهمها انشاء وزارة للبيئة بموجب القانون رقم (37) لسنة/2008 استناداً للقرار المرقم (29) الذي بين ان الاسباب الموجبة لتأسيس الوزارة هي "حماية البيئة وتحسينها وجعل وزارة البيئة



اضافة لعدة قو انين و انظمة وهي \}(قانون حماية وتحسين البيئة المرقم (27) لسنة/2009 [15]، النظام

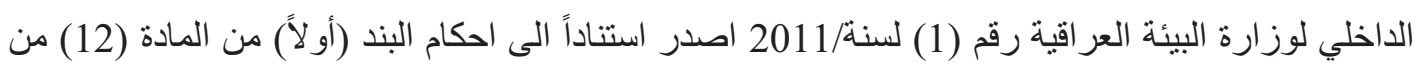
قانون وزارة البيئة المادة (3) من قانون حماية وتحسين البيئة رقم (27) لسنة/2009 [16]، (قانون الحفاظ على الثروة الهيدروكربونية) رقم (84) لسنة/1985 [17]، نظام الحفاظ على الموارد البيئية رقم (2)

لسنة/2001 [18].

2-3 دور الرقابة البيئية في استثامة الموارد الطبيعية المتمثئة بـ (الماء والهواء والتربة

والمياه الجوفية)

ان للرقابة البيئية دوراً يتركز على التأكد الدوري من مدى تطبيق المعايير البيئية الموضوعة بناءً على القوانين و الانظمة والتعليمات النافذة وفق برنامج تدقيق بيئي يعد منهجاً لعمل (الجهات الرقابية البيئية المستقلة

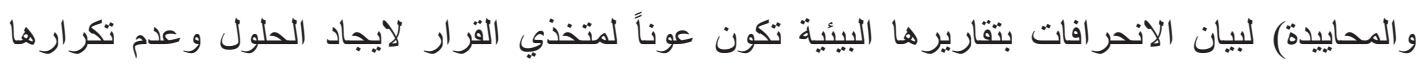

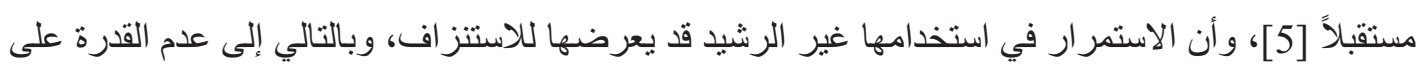
الوفاء باحتياجات الأجيال القادمة [25]، فاصبح من الضرورة خلق علاقة أخلاقية تربط بين الإنسان و البيئة،

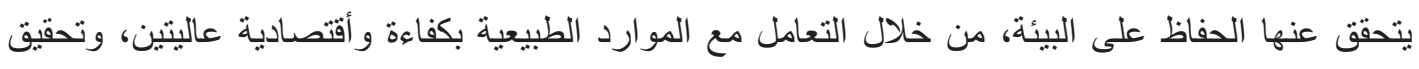

العدالة في الاستفادة من الموارد الطبيعية بمختلف أنو اعها للمستخدم الحالي و الاجيال القادمة [19]. لقد بينت تقارير الرقابة البيئية وكذللك آراء المختصين على مستوى العالم بخلاصة مفادها عدم الاكتفاء بتغير أنماط استهلاك تلك الموارد بل لابد من السعي للحد من الفقد والإفر اط في استخدامها و ايجاد الحلول لمعالجة شحتها مستقبلاً مع الاخذ بنظر الاعتبار اللجوء الى طرق حديثة في معالجة مخلفات استخدامها كالمستنقعات الملوثة و التي تعد احد التحديات و المعوقات التي تقف بوجه استدامة الموارد الطبيعية، لانعكاس ذللك في ظهور 
مشكلات صحية وبالذات الأمر اض والأوبئة المستعصية، مثال ذللك مرض الكوليرا ومشاكل في التنفس و غير ها الكثير [21،20، 2012].

\section{4- مفهوم استثامة الموارد الطبيعية وتُعريفها:}

ان الحفاظ على الثروات الطبيعية للاجيال القادمة كان السبب الرئيسي وراء السعي لاستدامة الموارد الطبيعية



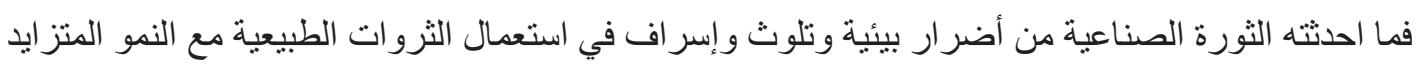
في كل من الجانب الاقتصادي والنظم الاجتماعية اضافة للنمو المضطرد في اعداد سكان العالم ادى الى لى ضرورة الانتباه الى اهمية الحفاظ على البيئة بما تحتوية من خير ات طبيعية [22].

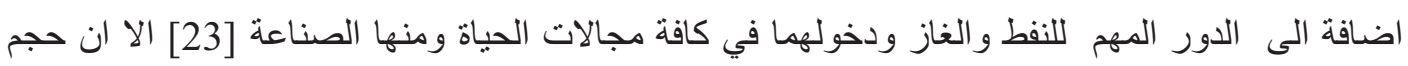
التلوث الناجم عن عملية استخراج النفط من الابار النفطية يعود بالضرر على البيئة المحيطة للشركات

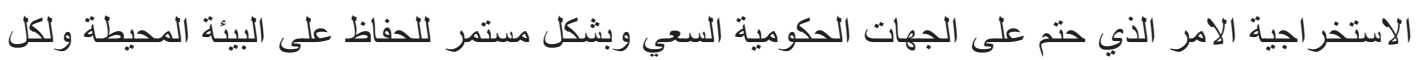

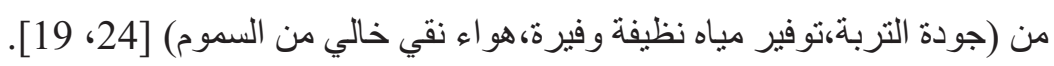
وقد عرفت الاستدامة على انها "تلك الموارد والظو اهر الطبيعية التي لادخل للانسان في تكوينها ولكنه يعتمد

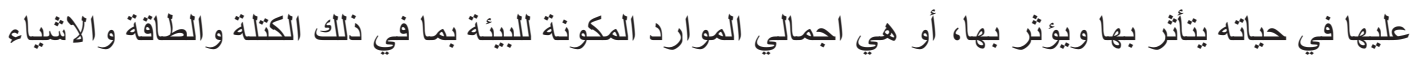
البيولوجية و الاشياء الحية" [25]. وعرفت ايضاً بأنها "موارد طبيعية قابلة وغير قابلة للتجدد تعد المصدر الرئيسي لحياة الكائنات الحية وديمومتها" [26]. التعريف الاجر ائي لاستدامة الموارد الطبيعية "هي الحفاظ على ديمومة واستمر ارية وجود المو ارد الطبيعية

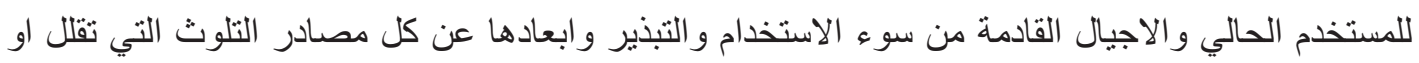
تعدم النفع الطبيعي المتحقق من وجودها للكائنات الحية ضماناً لاستمر ار الحياة على كوكبنا".

\section{1-4 تصنيف الموارد الطبيعية:}

قد صنفت الموارد الطبيعية بحسب وجهة نظر الجغر افييون الى [19، 25، 26]:1. مو ارد طبيعية متجددة غير قابلة للنفاذ: توجد بكميات كبيرة جداً وتثمل (الموارد المائية و المناخية و الفلكية) و هي متجددة باستمر ار و غير قابلة للنفاذ.

2. موارد طبيعية متجددة قابلة للنفاذ: هي موارد يمكن ان تتجدد بشكل طبيعي اذا توفرت لها الظروف المناسبةو ان هذه المو اد تستنزف نتيجة الاستغلال المكثف لها مثل (الحيو انات البرية و الغطاء النباتي الطبيعي). 
3. موارد طبيعية غير متجددة قابلة للنفاذ: منها الثروات الباطنية ومصادر الوقود الاحفوري والنفط والغاز و التي تكونت عبر الزمن و لايمكن صنعها من قبل الانسان اذ تم استهلاكها بكميات اكبر من قدرة الطبيعة على انتاجها يؤدي الى نفاذها كما يضاف لها المياه العذبة و المالحة وذللك للادور الذي تقدمه كلُ منهما للبيئة.

2. موارد مستبدلة وغير مستبدلة: تنقسم الى نوعين مورد طبيعي يمكن استبداله بمورد اخر كما في (النفط بدلاً من الفحم...) ومورد طبيعي لايمكن استبداله بمورد آخر كما في الاكسجين و الماء. 3. موارد طبيعية كامنة: هي موارد طبيعية موجودة لايمكن استخدامها او الوصول اليها في الوقت الحالي

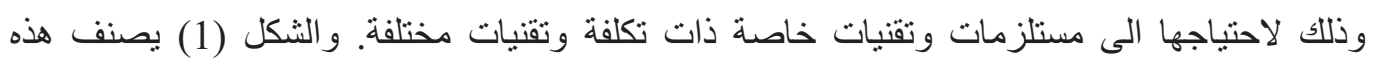
الموارد الطبيعية.

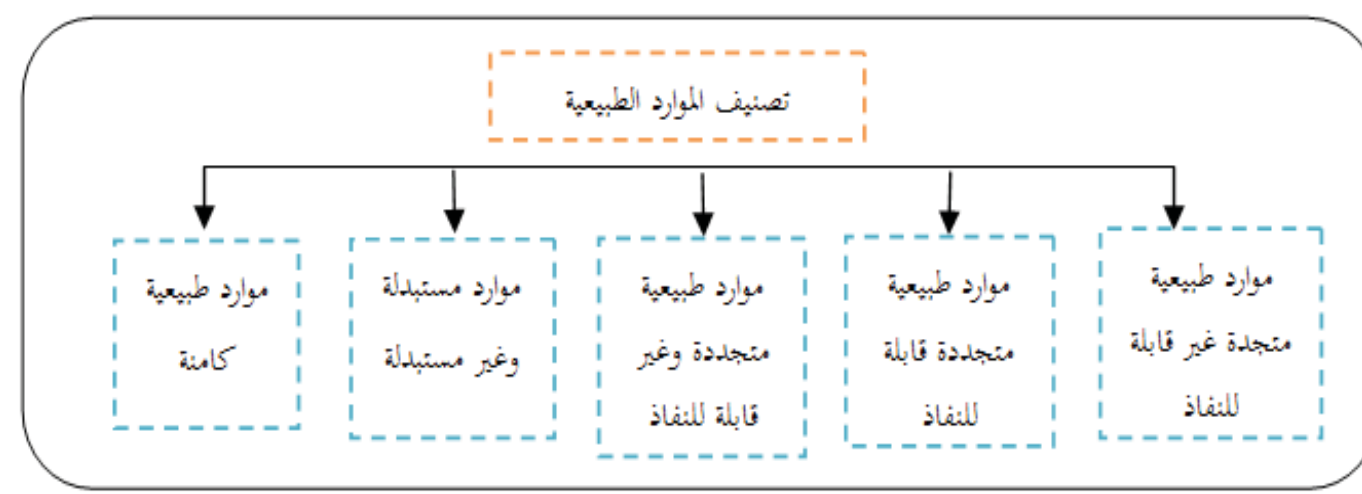

الثكل (1) تصنيف الموارد الطبيعية

2-4 المعوقات التى تواجه استدامة الموارد الطبيعية: التئوث (pollution)

من اهم المعوقات التي تواجه استدامة الموارد الطبيعبة المتمثلة بـ (الماء و الهو اء و التربة والمياه الجوفية) هو التلوث ويمكن تقديم صورة مختصر وو اضحة عنه في ادناه:اذ يعرف التلوث بانه "اطلاق عناصر او مركبات او مخاليط غازية او سائلة او صلبة الى عناصر البيئة والتي هي الماء و الهو اءو التربة مما يؤدي الى احداث تغيير أ في جودة هذه العناصر " [28].

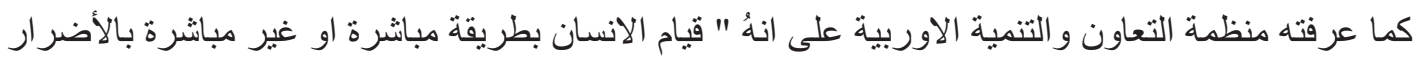
بالبيئة الطبيعية و الكائنات الحية" ويعد تعريفها من اهم تعريفات و اشملها [29]. التعريف الاجر ائي للتلوث "هو الضرر المباثر وغير المباشر لممارسات الانسان اليومية على عناصر البيئة طبيعية التي تفقد كلا اوجز ء من جودتها جر اء هذه الممارسات". يمكن تقسيم التلوث حسب مصدر الملوثات الى [2، 24، 28، 30]:- 
1- تلوث ناتج عن مصادر تلوث طبيعية كالأتربة التي تحملها الرياح ،والرماد و الغازات المتصاعدة من

البر اكين، و الاوزون (O3 ) الناتج من ظاهرة البرق ،وما ينتج عن التحلل الطبيعي للمو اد النباتية.

2- تلوث ينتج بفعل الانسان ويشمل ما ينتج عن الانشطة الصناعية الطبيعية للانسان كاعمال الحفر والهدم و البناء والصناعات الكيميائية والبترولية، ملوثات حرق الفحم والنفط والمخلفات الصناعية ومجازر

$$
\text { اللحوم) و غير ها الكثير [29]. }
$$

3- حرق الوقود المستعمل المتحجر من العو امل الاساسية في تلوث هو اء المدن الصناعية المكتظة بالسكان. 4- تسريب النفط الخام في مياه البحار والمحيطات بسبب الحوادث وعدم الصيانة الدورية وكذلك إطلاق الهيدروكربون الناتج من مشاعل الغاز والتي تؤدي بدور ها تلوث الغلاف الجوي.

5- تصريف النفايات السائلة في البيئة المحيطة من قبل شركات النفط أثناء الاستكثاف أو المسوحات الزلز الية التي تقوم بها تلك الثركات و التي تستخدم قصاصات الحفر وطين الحفر و السو ائل لتحفيز الإنتاج.

\section{انواع التثلوث:}

1- 1- 1التلوث الذي يتعرض للهُ الماء:-

يعد الماء من اهم الموارد الطبيعية فهو نبض الحياة على الارض وهو نعمة من الله للبشرية، ويقسم الماء الى (مياه المحيطات العالمية ،المياه الجوفية الباطنية، المياه الجوفية البينية ،المياه الجليدية المتجمدة، مياه البحير ات

و التربة وبخار الماءو الانهار) [25، 31]. يتعرض الماء (Water pollution) للتلوث من عدة مصادر و التي يبينها الثكل (2) أدناه وهي:-

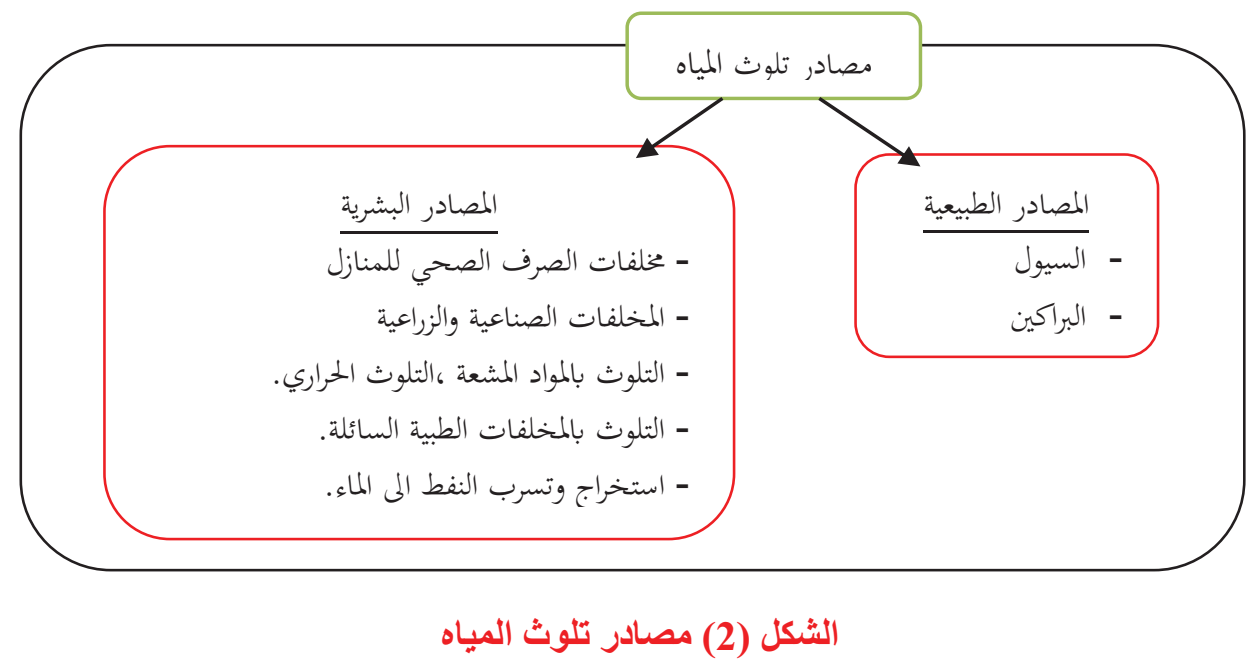




$$
\text { يبين البحث فيما يلي بعض مصادر تلوث الماء التي لها علاقة بموضوع البحث وهي:- }
$$

أـ مصافي النفط: ان عملية تصفية النفط الخام تعد من اعقد انواع الصناعات الكيميائية لان النفط خليط معقد لعدة مركبات كيميائية يجب فصلها الى اجز اء متجانسة الى حدٍ ما لكي يتمكن من اداء وظيفتهُ [28]، و ان عملية استخر اج النفط تتضمن ملوثات صلبة معلقة مع النفط وهي "المواد القابلة للترسيب" و التي تكون على شكل رواسب طينية عندما تختلط بالمو اد الغروية تؤدي الى تلوث الماء كما في الثكل (3)،

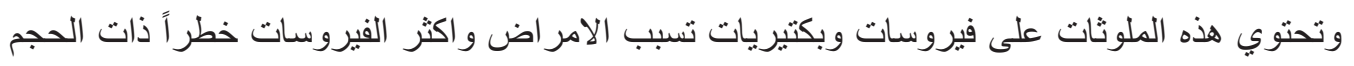
الصغير التي لايمكن اكتشافها الا من خلال اجر اء اختبار ات خاصة بذللك و التي تؤُثر سلباً على حياة كل

الكائنات الحياة [32 32 32]

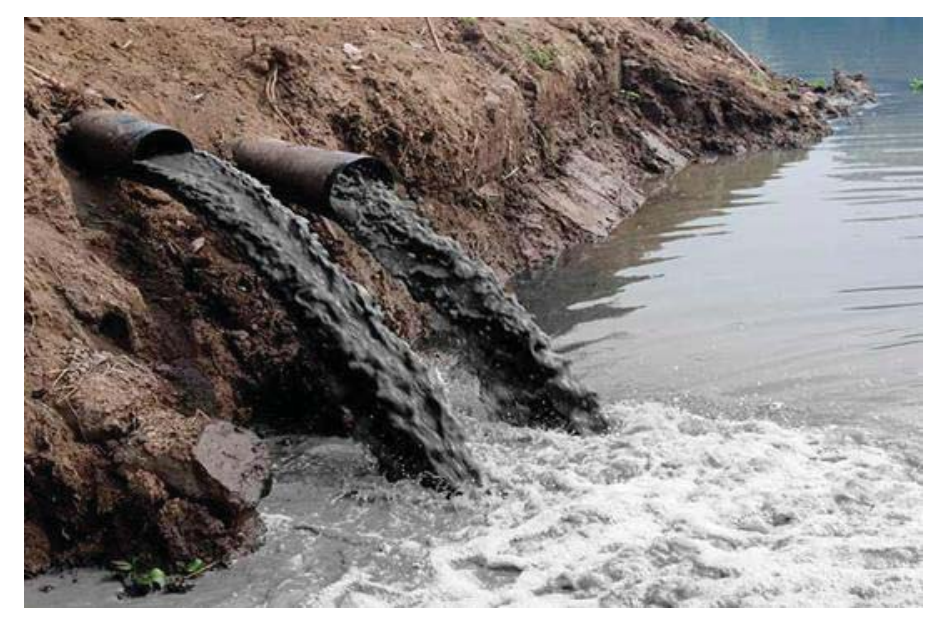

الثكل (3) بركة من الماء المصاحب الملوثُ بالنفظ الخام في حقل الاحلب.

تحتاج عملية استخر اج النفط إلى استهلاك كمية كبيرة من المياه إذ يستهلك في بعض الآبار النفطية ما يعادل اربعة بر اميل أو أكثر من الماء لقاء كل برميل مستخرج من النفط مما يثير التساؤل هل أن زيادة استخر اج النفط الخام سيكون على حساب استهلاك المياه؟ الجواب/ نعم:- ان استخدام هذه الكمية الكبيرة من المياه ستؤدي إلى شح المياه تدريجياً وبعد مرور الزمن في المناطق المجاورة للحقول النفطية وصولاً الى شحتها عالمياً والتي هي موضوع البحث الذي سيوضح فيه انعكاس ذلك على استدامة الموارد الطبيعية للاجيال القادمة ومدى تأثنير التلوث عليها. بـ ان من المصادر الاخرى لتلوث الماء الاملاح الذائبة مصدراً لتلوث الماء والتي معظمها تكون غبر عضوية مثل الكربونات و البيكربونات، كما ان الزيوت التي تتسرب الى الماء اثناء استخر اج وانتاج

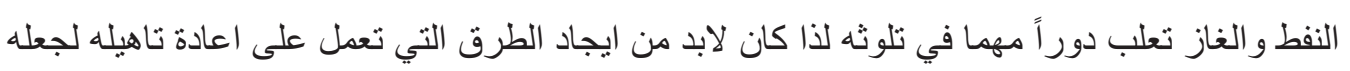
صالحاً للاستخدام مرة ثانية حفاظاً على هذا المورد الطبيعي المهم من النفاذ. 
يمكن تقسيم طرق معالجة تلوث الماء بثلاث مر احل وهي [3, 24 [وحدات المعالجة الاولية/و تستخدم لاز الة المواد المعلقة بواسطة الترسيب والمواد الطافية بواسطة اجزةة التعويم ، وحدات المعالجة الثنانوية/ وتقوم اساساً على طرق المعالجة البيولوجية ، وحدات المعالجة المتقدمة/ وتختص باز الة الملوثات التي تعذر از التها بالمعالجة البيولوجية و اهم طرقها عمليات الامتز از و التبادل الايوني).

يعد الهواء من اساسيات الحياة لذا فان انقطاعه لعدة دقائق يكون كافي لهلاك الانسان والحيوان، وتكمن خطورة تلوث الهو اء في كونه لايرى وان الانسان باخذه مبانشرة الى جسمة عن طريق التنفس، وان صعوبة التلوث تزداد بضعف الوسائل العلمية والتقنية المستخدمة في الاقلال او التخلص من التلوث على الرغم من لن التقدم الكبير و العلمي في كافة مجالات الحياة [29 ، 313].

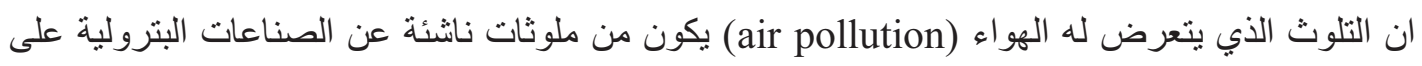
شكل ملوثات غازية تنتشر في الهواء وقد تتفاعل فيما بينها مسببة اضراراً كبيرة في الهواء كما مبين في لهي الثكل (4)، و ايضاً من المخلفات السائلة الداخلة في هذه الصناعة التي تحتوي على الاحماض و القواعد و الاملاح او تكون عضوية التي تتمثل بالزيوت و الثحوم [34].
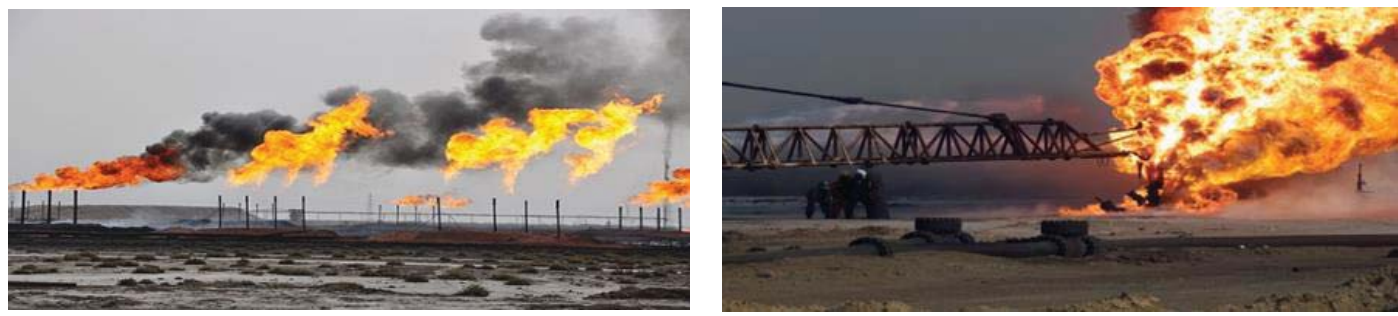

الشكل (4) تلوثث الهواء في حقل نفط خانة وشرق بغداد.

3- 3 التلوث الذي تتعرض لهُ التربة:-

ان اعمال التققبب عن النفط تؤدي الى احداث تغيرات جوهرية على المناظر الطبيعية بسبب قلب التربة باستخدام معدات ثقيلة وجر افات وشاحنات التي تؤدي الى انهيار ارضية التربة ، فعلى الرغم من معالجة التربة بعد استخر اج النفط الخام فانها لن تعود بنفس الخصوبة و النشاط الانتاجي لها لتعرض تركيبتها الاساسية للتلف[35]، الأمر الذي يعود بالضرر على التربة بشكل عام وعلى الار اضي الزر اعية بشكل خاص ومستوى

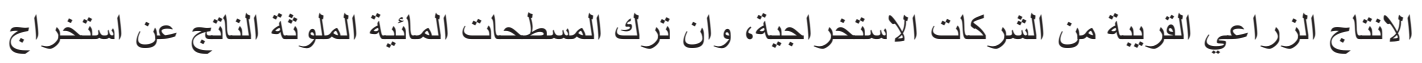

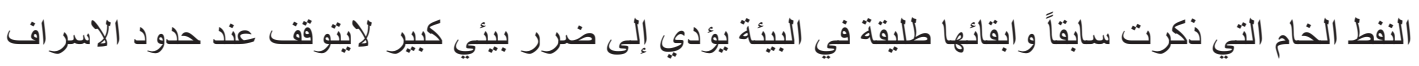
و التبذير في الماء العذب بل يمتد الى تلوث التربة المحيطة بالثركات الاستخر اجية ومنها عينة البحث [29] و هذا مايمكن ملاحظته كما في الثكل (5). 


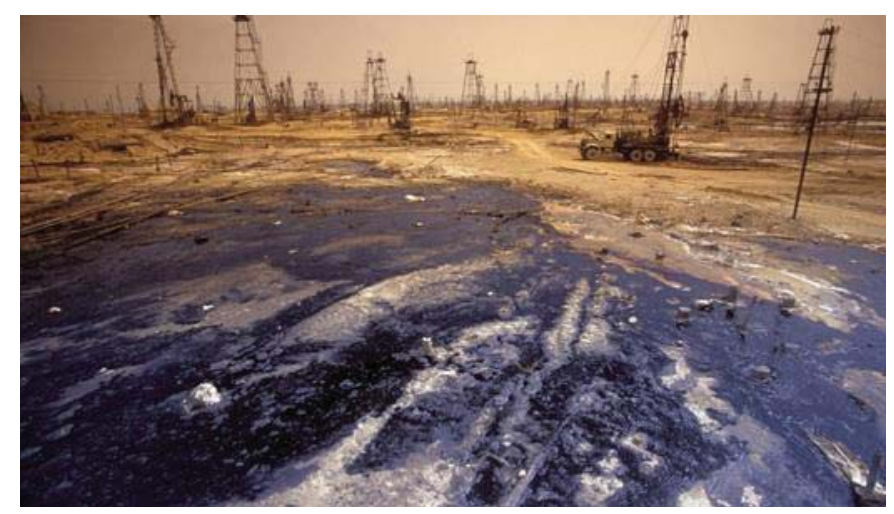

$$
\text { الشكل (5) تلثوث التربة في حقل بدرة. }
$$

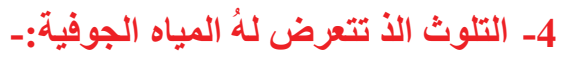

يعد تلوث المياه الجوفية نتيجة حتمية للتلوث الذي اصاب كل من الماء والهواء والتربة فالآثار المتعلقة بالمشاكل المهمة والأساسية المصاحبة لوجود النفط ولعمليات استخراجه ووجود كميات من البرك النفطية الكبيرة و الحاوية على النفط الخام أو المياه ذات المحتوى النفطي العالي و المتولدة إما بسبب أخطاء تشغيلية أو ولئ تصميمية أو بسبب التصاريف السائلة غير المعالجة للمياه إلى التربة المجاورة أو المصادر المائية فانها ستؤدي إلى حدوث تلوث كبير يستهدف التربة او المياه السطحية و الجوفية [29].

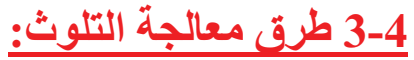

طرق المعالجة تختلف حسب نوع التلوث و الذي يعد من المعوقات التي لاتقل اهية عن التلوث نفسهُ اذ ان تحديد الطريقة المناسبة للحد من التلوث او عدم السماح بحدوثة عن معدلات معينة تحتاج الى خبرة علمية

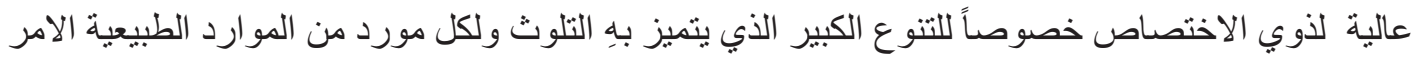
الذي يضع على عاتق الثركات المسبية للتلوث ان تأخذ بنظر الاعتبار تكلفة الحد من التلوث و عدم السماح بتكر ار حدوثه وطرق علاجه عند وضع خططها المستقبلية، بوضع ضمن خطة عملها السنوية وسائل للحد من

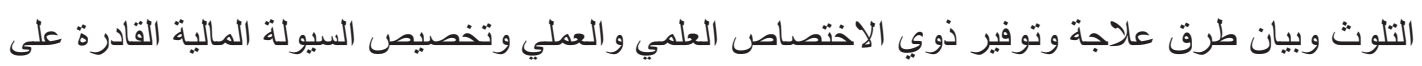
سد تلك المستلزمات و اعداد تقارير بذللك شانه شان التقارير المالية [3]. و هناك طرق عدة لمعالجة كل نوع من انواع التلوث بما يناسبه منها على سبيل المثال مرشحات الهو اء لمعالجة تلوث الدقائق و الحقن بالحجر الجيري للتحكم بثنائي اكسيد الكبريت المنتشر في الهو اء الناتج من حرق الوقوده،

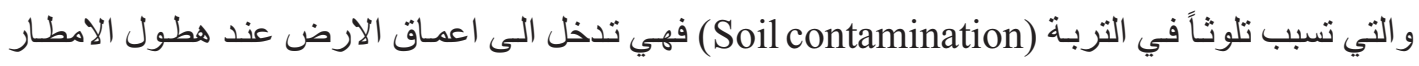

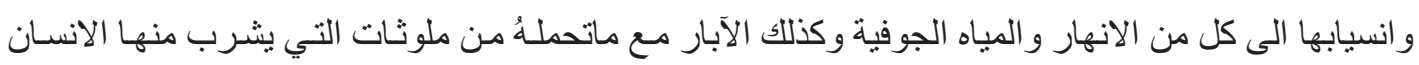

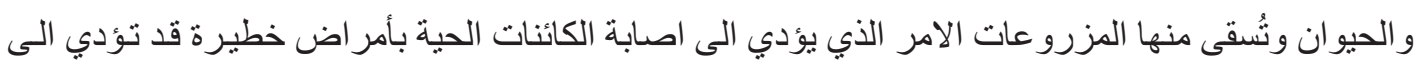


و هذا يعني ان تاثير تلوث الهواء لايقف عند هذا الحد فان هطول الامطار بيساعد على انتشار التلوث الذي لايبقى محصور اً ضمن الماء والهو اء فقط بل يمتد الى اكثر من ذلك فنزول المطر الملوث على لهئ الانهار والابار و التربة سيؤدي الى تلوثها جميعاً وامتصاص الارض لهذه المياه الملوثة يؤدي ايضاً الى تلوث المياه الجوفية.

5- الجانب العملى للابح:

تم تطبيق الجانب العملي من البحث على شركة نفط الوسط شركة عامة (عراقية الجنسية) وهي احدى تشكيلات وزارة النفط العر اقية و التي تأسست بموجب القرار المرقم (155) لسنة/2010 و الصادر من الامانة العامة لمجلس الوزر اء العر اقي بموجب كتابها المرقم (ش.ز /205/4/1/10 وزارة النفط/مكتب وزير النفط للهيئات [36]، وذلك بتوزيع عدة نسخ من قائمة الفحص على عينة من موظفي

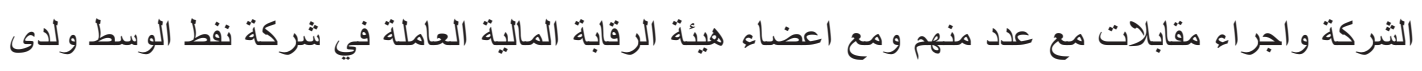
الشركة سابقة الذكر عدة حقول وهي:1 - 1 - 1قل نفط خانة

يقع حقل النفط خانة على الحدود العر اقية الإير انية بطول (•r) كم وعرض (ع, (O) كم، فيما يبلغ إرتفاعه

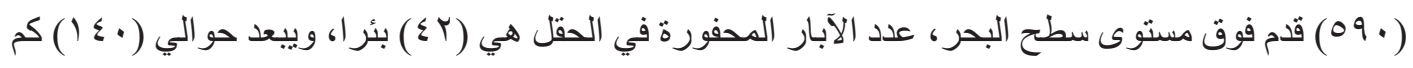
شمال شرق بغداد. 2- 2 - 2 - 2قل شرقي بغداد

هو عبارة عن طية محدبة متأثرة بفو القى طولية وعرضية تقسم الحقل إلى أقسام منفصلة كل منها يحتوي على نفوط ومستويات تماس للموائع تختلف بإختلاف مواقع المكامن بالنسبة للوضع التركيبي فيها، عدد الأبار المحفورة في الحقل (VV) بئر اً موز عة على مناطق الحقل الستة (المنطقة الجنوبية الأولى والثانية، و المنطقة السكنية، ومنطقة الر اشدية، ومنطقة التاجي، ومنطقة النباعي). 3- حقل الاحدب

يقع حقل الاحدب على بعد(180) كم جنوب شرق بغداد في محافظة و اسط تم اكتثاف الحقل عن طريق اعمال

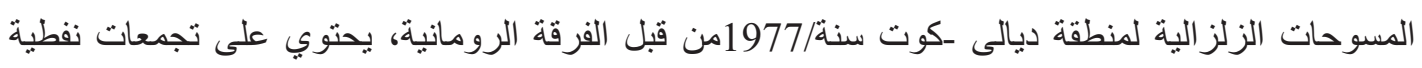
منباينة في (الهارثة، التنومة، الخصيب، المشرف، الرميلة، المودود، نهر عمر و الثعيبة) و الثكل (6) يبين موقع الحقل من محافظة و اسط الكوت. مابـ 


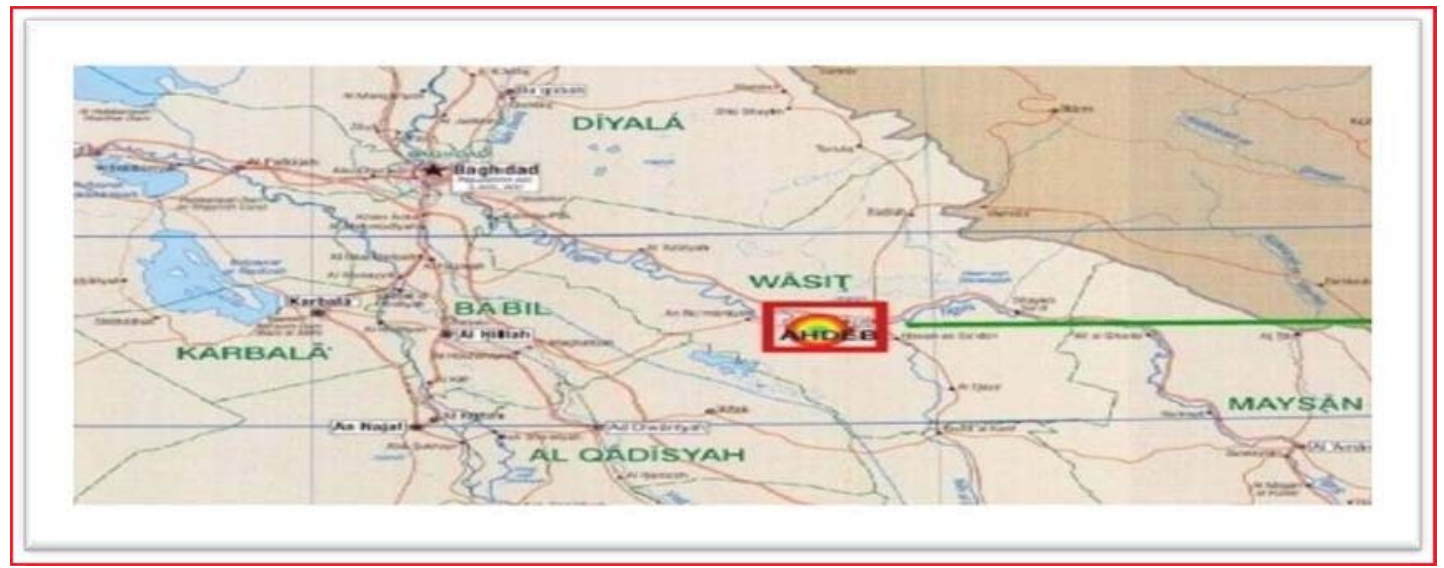

شكل (6) مخطط موقع حقل الاحلب في محافظة واسط (الكوت).

يقع حقل بدرة النفطي في محافظة واسط ويبعد حو الي(160) كيلومتر الى الجنوب الثرقي من محافظة بغداد ويعتبر حقلاً حدودياً مشتركاً مع جمهورية إيران الاسلامية أذ يمتاز بنفطه الخفيف (API=35

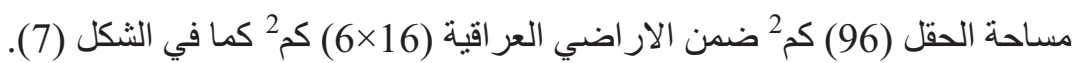

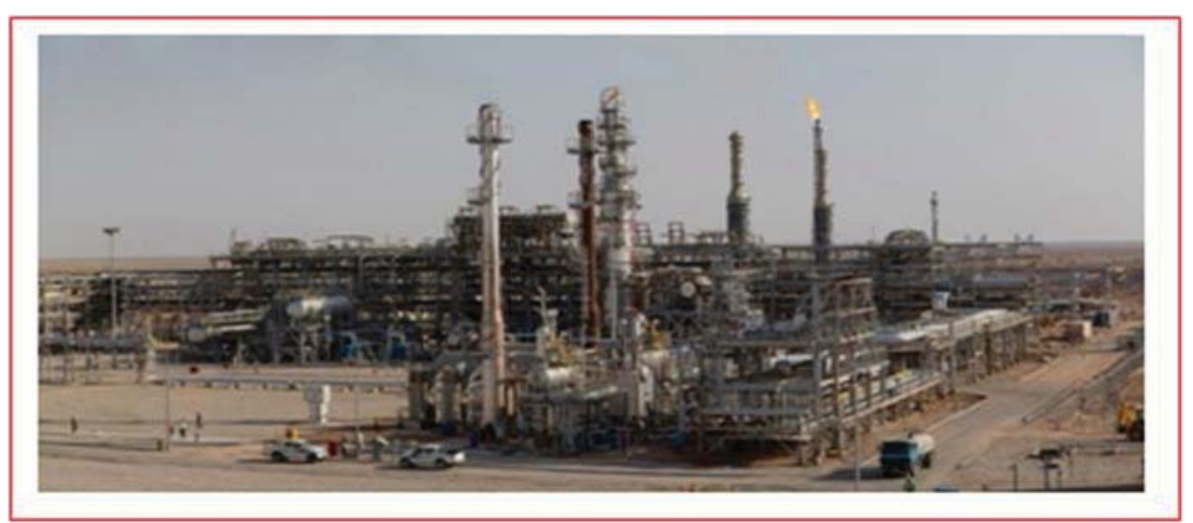

الثكل رقم (7) حقل بلرة في داخل الاراضي العراقية/محافظة واسط.

يوضح الجانب العملي الدور المهم للرقابة البيئية استكمالاً لما ورد عنها سابقاً والتي تعد من الطرق المهمة للحد من التلوث واستدامة الموارد الطبيعية من خلال استخدام قائمة فحص نابعة من برنامج التدقيق البيئي و المعد من قبل ديوان الرقابة المالية الاتحادي، اذ تضم فقرات قائمة الفحص مجموعة من الاسئلة وجهت لعدة موظفين مختصين بشكل مباشر لبيان الاثار الناجمة عن عمليات استخر اج النفط واضرار ها على البيئة في 
برها وجو ها وماءها و المتمثل بالماء المصاحب لعمليات استخر اج النفط الخام لما للهُ من آثار ضارة مبانشرة على البيئة وكذلك المو اد التي تستخدم في الوحدات الانتاجية والخدمات المر افقة للعمليات الاستخر اجية مثل المو اد الكيمياوية المستخدمة في معالجات مياه الحقن كمادة (دايكرومات البوتاسيوم أو الصوديوم) مانعة التآكل التي يجب التعامل معها بكامل الحذر وبتطبيق كافة التعليمات النافذة والمعايير الدولية وتطبيق أمثل الثروط المطلوبة للخزن و النقل و الاستخدام والمعالجة وتطبيق قوائم السلامة الخاصة بكل مادة لاثار ها السلبية على ولى وائه حياة الكائنات الحية، لكن على الرغم من ذلك تعد عملية الرقابة غير فعالة وقادرة على مو اجهة التلوث البيئي

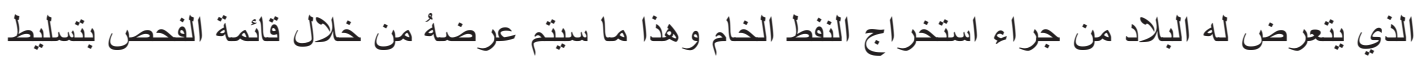
الضوء على الجو انب الريئسية والمهمة المسببة للتلوث المتمثل بالماء المصاحب كما في الجدول (1). جدول (1) تحليل نتائج قائمة الفحص

\begin{tabular}{|c|c|c|c|c|}
\hline \multirow[t]{2}{*}{ كلا } & \multirow[t]{2}{*}{ نعم } & \multirow[t]{2}{*}{ التفاصيل } & \multicolumn{2}{|c|}{ 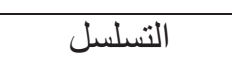 } \\
\hline & & & 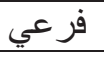 & رئيسي \\
\hline & & طبيعة نشاط الثركة وحسب التساؤو لات التالية:- & & 1 \\
\hline & $*$ & هل موقع الشركة الاستخر اجية بعيد عن المدينة المناطق السكنية. & أ & \\
\hline * & & هل موقع الثركة الاستخر اجية بعيد عن المدينة المناطق الزر اعية. & ب & \\
\hline & $*$ & هل للشركة اجراءات حماية بيئية من التلوث الناتج من عملية استخر اج النفط الخام. & $\rightarrow$ & \\
\hline & $*$ & هل تخضع الشركة للقو انين و التشريعات البيئية وحسب طبيعة نشاطها. & د & \\
\hline & $*$ & 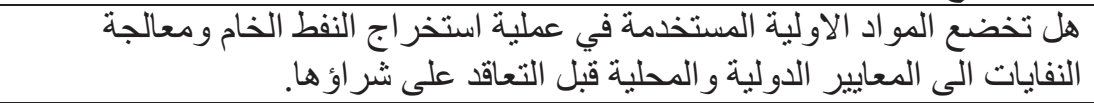 & هـ & \\
\hline & $*$ & هلى البيئة. المو اد الاولية و المخرجات و النفايات المستخدمة في نشاط الثركة لها ضرر & 9 & \\
\hline & $*$ & البيئي. ان الاسلوب المنبع في معالجة النفايات و التخلص منها يقلل من مدى التلوث & j & \\
\hline & $*$ & هل هناك اثار بيئية اخرى لنشاطات الثركة الاستخر اجية. & $\tau$ & \\
\hline & & فحصى مايلي:- فر اسة الجدوى الفنية والاقتصادية للنشركة الاستخر اجية من خلال احتو ائها & & 2 \\
\hline & * & هل تقوم الثُركة الاستخر اجية بتقويم الاثر البيئي السلبي لها. & أ & \\
\hline & $*$ & هل تتضمن الدر اسة وسائل حديثة لتلافي ومعالجة مسببات التلوث. & ب & \\
\hline$*$ & & هل يتم احتساب تكاليف در اسة معالجة التلوث في (ب) اعلاه بالنسبة الى مقدارهُ. & $\rightarrow$ & \\
\hline & $*$ & هن مز اولة نشاطها. الدرة طرق لمعالجة الحالات الطارئة و المحتملة للتلوث التي تنشئ & د & \\
\hline$*$ & & بيئًاً هنالك در اسة سنوية؛ تتضمن بدائل ذات تقنيات تعمل على تقديم مخرج انظف & o & \\
\hline & $*$ & هل تتضمن الدر اسة طرق لتقليص و اعادة تدوير المخلفات . & 9 & \\
\hline$*$ & & هلثاء تتضمن اولتها لنشاطها. & j & \\
\hline & $*$ & 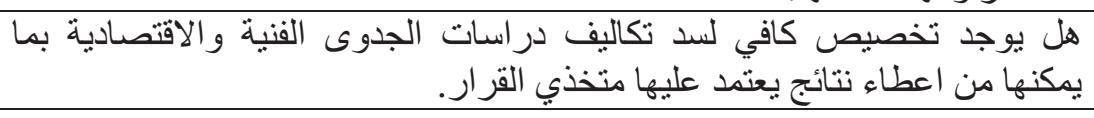 & ح & \\
\hline & & نظم السلامة و البيئة:- & & 3 \\
\hline
\end{tabular}




\begin{tabular}{|c|c|c|c|c|}
\hline \multirow[t]{8}{*}{$*$} & & المناطق هنالك نظم سلامة متخصة الزر اعية. & أ & \\
\hline & $*$ & 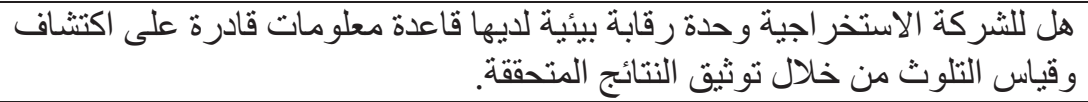 & ب & \\
\hline & $*$ & والجهات تقوم الوحدة الرقابية بفحوصات دورية وترفع بها تقارير الى الادارة العليا & $\rightarrow$ & \\
\hline & $*$ & هل للشركة الاستخر اجية ملاكات رقابية متخصصة علمياً و عملياً. & د & \\
\hline & $*$ & هل للشركة الاستخر اجية اجهزة مر اقبة لقياس ومر اقبة التلوث وبحسب نو عه. & ○ & \\
\hline & $*$ & هل للشركة الاستخر اجية اجهزة لمعالجة التلوث وبحسب نو عه. & 9 & \\
\hline & $*$ & هل ان المو اد الاولية المستخدمة في نشاط الشركة ذات منشأ رصين. & j & \\
\hline & $*$ &  & 乙 & \\
\hline & $*$ & هل هناك نظاماً للحريق وحسب مصادر حدوثة. & b & \\
\hline$*$ & & و هل تستخدم الشركة معدات حديثة لتنقية الهو اء. & ي & \\
\hline \multirow[t]{5}{*}{$*$} & & عن الدى الثركة الاستخر اجية اجهزة ورحدة معالجة المياه و الهو اء و والتربة مطورة للحد ومعالجة التلوث الناجم & 5 & \\
\hline & $*$ & نو عل هنالك صيانة دورية لكل من الاجهزة و المعدات الموجودة في الثركة مهما كان & J & \\
\hline & $*$ & الدورية لهم وكلَ انظمً سلامة حسب مجال للعاملين فيله الثركة من ملابس خاصة و اجر اء الفحوصات & r & \\
\hline & & اجر اءات الفحوصسات البترو كيمياوية:- & & 4 \\
\hline & $*$ & 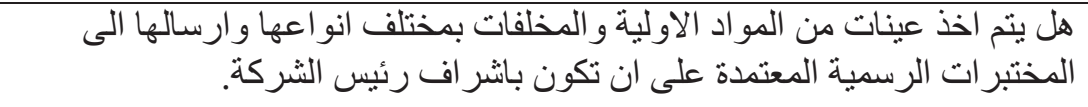 & أ & \\
\hline \multirow[t]{4}{*}{$*$} & & هل يتم مقارنة نتائج فحوصات المو اد الاولية والنفايات مع المعايير الدولية لقبولها. & $\varphi$ & \\
\hline & $*$ & 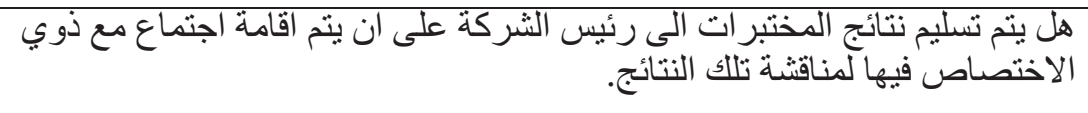 & $\rightarrow$ & \\
\hline & $*$ & هلت يتم ارشفة كقاعدة بياناتج مع توصية الاجتماع بموجب محضر لكي يتم الاستفادة منه & د & \\
\hline & $*$ & يحدثها نشاط الحلول المناسبة في حالة ارتفاع نسب الاستخر اجية. & 0 & \\
\hline \multirow[t]{2}{*}{$*$} & & 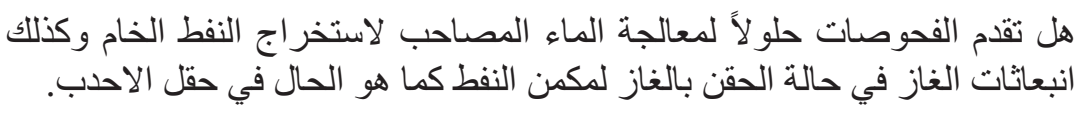 & و & \\
\hline & & التحليل المالي للبيئة على ان تتوفر بها المتطلبات التالية:- & & 5 \\
\hline \multirow[t]{2}{*}{$*$} & & الموجودات الثابتة البيئية للشركنة القسم المالي للشركة الاستخر اجية خاصة للسيطرة على & i & \\
\hline & $*$ & ان تكون لدى الشركة الاستخر اجية نظام تكاليف للموجودات الثابتة البيئية لها. & ب & \\
\hline$*$ & & 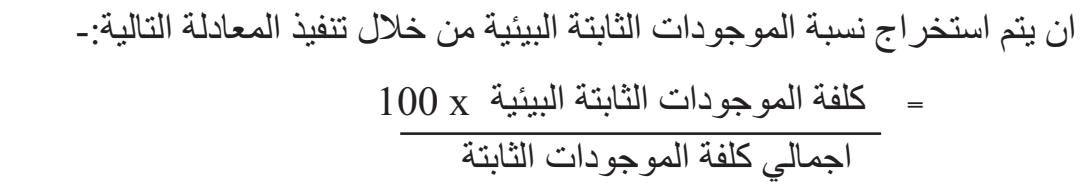 & $\rightarrow$ & \\
\hline
\end{tabular}




\begin{tabular}{|c|c|c|c|c|}
\hline \multirow[b]{2}{*}{$*$} & * & | تحديد نسبة الاستثمار بالموجودات الثابتة الخاصة بحماية البيئة . & \multirow{2}{*}{$\begin{array}{l} \\
\\
\end{array}$} & \\
\hline & & تلحنيد نسبة المصاريف البيئية الى اجمالي المصاريف التشغيلية للشركة & & \\
\hline$*$ & & تحديد جحم النشاط المتعلق بحماية البيئة المتبع في الشركة الاستخر اجية & 9 & \\
\hline$*$ & & تحديد نسبة حجم النشاط البيئي الى نسبة اجمالي نشاط الشركة الاستخر اجية & j & \\
\hline$*$ & & 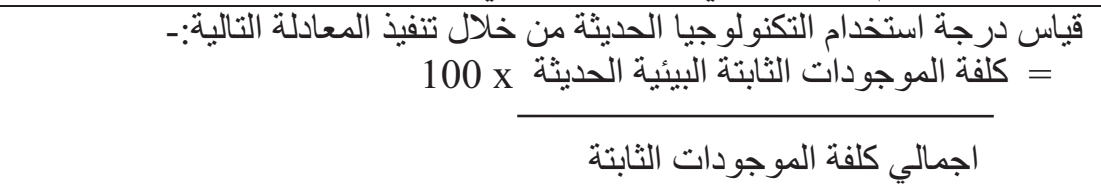 & $\tau$ & \\
\hline 1 & 2 & & & 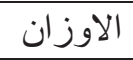 \\
\hline 16 & 26 & & & 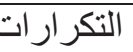 \\
\hline 16 & 52 & & & 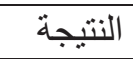 \\
\hline & 1.619 & & بي آ & 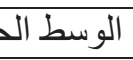 \\
\hline & 0.809 & المطابقة & كُ لمد & 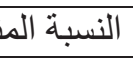 \\
\hline & 0.191 & & & 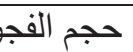 \\
\hline
\end{tabular}

$$
\text { اجريت الحسابات بالمعادلات الآتية [7]:- }
$$

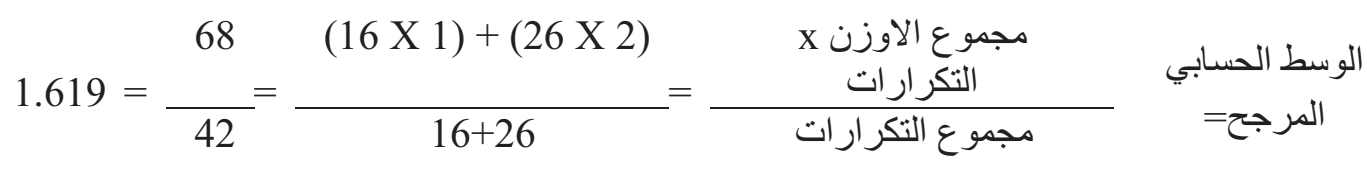

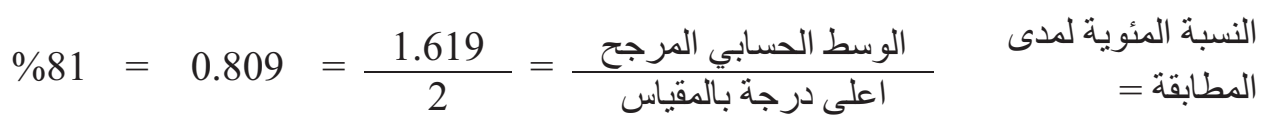

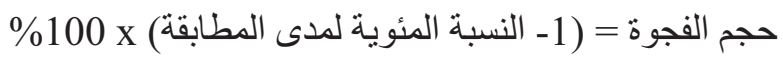

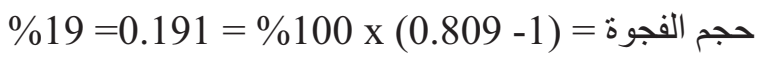

يلاحظ من الجدول اعلاه النسبة المئوية لمدى المطابقة والتي تعتمد على مقدار الوسط الحسابي المرجح الذي نحصل عليهِ (منمثلاً بالبسط) و المقسوم على المقام الذي يمثل أعلى درجة بالمقياس هي مقدار ثنابتـ تكون


الابتعاد عن الحالة المثالية بنسبة مدى المطابقة و التي تقابل الوسط الحسابي المرجح ومقدارهُ (2) بعد التقريب،

$$
\text { وان تناقص الفجوة يكون بفعل عمليات التحسين التي تقربها الى (نعم). }
$$

\section{5- 5 مناقشُّة نتائج قائمة الفحص:}

اعتمد الاسلوب الاحصائي (التحليل الوصفي) في استخر اج الوسط الحسابي المرجح والنسبة المئوية لمدى مطابقة عمل شركة نفط الوسط شركة عامة (عر اقية الجنسية) وهي احدى الثركات الاستخر اجية العراقية 
لفقرات قائمة الفحص الواردة في الجدول اعلاه من خلال الاجابة على تساؤلاتها للمقاييس (نعم وكلا) و الاوزان المقابلة لها (2 ، 1). اذ تم من خلال قائمة الفحص الحصول على الاجابة الوافية والمتلى من خلال بيان الاثر السلبي للماء المصاحب لاستخر اج النفط الخام من الآبار النفطية المنمثلة بالمسطحات المائية الملوثة (البرك الملوثثة)، التي لئي

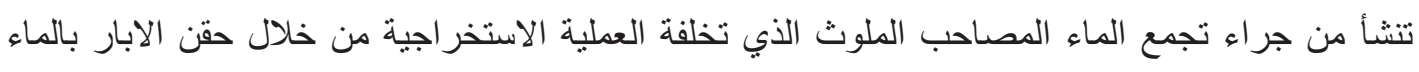
و التي تختلف كميته من بئر الى آخر حسب قوة ذللك البئر (المكمن) والتي تكون في اقل حقن برميل نفط خام

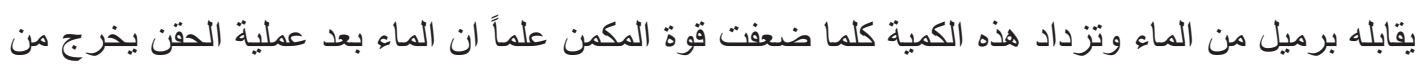
البئر يجمع على شكل مسطحات مائية ملوثة بالتالي تظهر مشكلة التلوث وتداعياتها التي بينت سابقاً على البيئة المحيطة للشركة الاستخر اجية. وان قائمة الفحص بينت مدى الانحر افات في عمل شركة نفط الوسط موضوع البحث عن المعايير الموضوعة

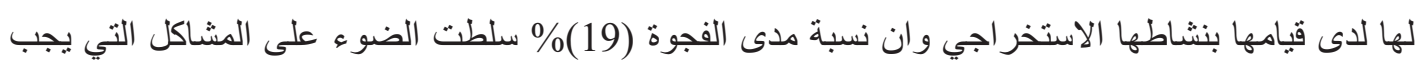
تلافيها من قبل ادارة الثركة العليا حفاظاً على البيئة من التلوث و المتمثل بالموارد الطبيعية من (ماءو وهو اء لهاء وتربة ومياه جوفية) وما تخلفة من سموم نأثر سلباً على الحياة لكل من الانسان والحيوان و النبات من خلال النال

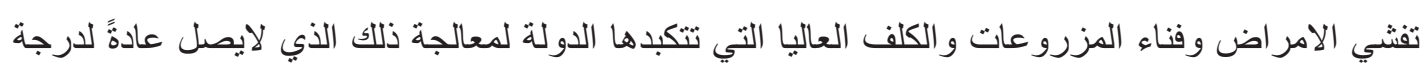

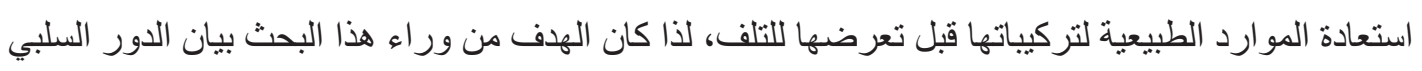

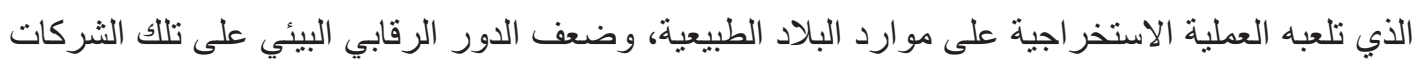

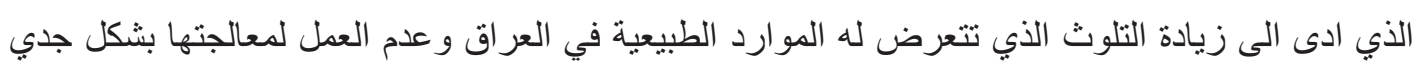

ومحاسبة الثركات المتسبية له.

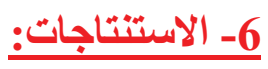

استناداً لنتائج تحليل قائمة الفحص الواردة في الجدول رقم (1) فقد تبين مايلي:1- عدم وجود نظام رقابي بيئي فعال قادر على تشخيص نقاط الخلل في نشاط الثركة بما يمكنه من مواجهة

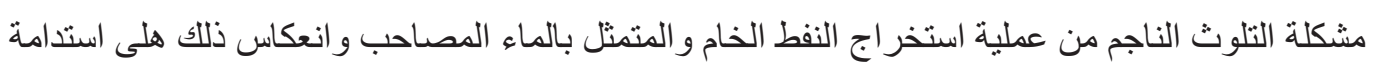

الموارد الطبيعية.

2- عدم وضع اولوية للحفاظ على استدامة الموارد الطبيعية المتمثلة بـ (الماء و الهوء و التربة و المياه الجوفية)

و هذا مانر اهُ جلياً في المسطحات المائية القريبة من الحقول النفطية التنابعة للشركة.

3- لم يأخذ بنظر الاعتبار قرب موقع الثركة من المناطق الزراعية التي تعد ثروة لابد من الحفاظ عليها من التلوث الناتج عن المسطحات المائية الملوثة وكنلك الغاز ات المنبعثة من محطات الاستخر اج. 
4- تفتقر شركة نفط الوسط الى نظم تعالج بها تأثير الملوثات على البيئة المحيطة بها والذي يمكن ملاحظتهُ على سعف اشجار النخيل القريبة من المسطحات المائية الملوثة المصاحبة لاستخر اج النفط الخام من لئل المكآمن التابعة لها التي تتعرض وبشكل مستمر للحرق.

5- عدم وجود معالجات حقيقية لكافة الحقول النفطية التابعة لها لمشكلة الماء المصاحب لاستخر اج النفط

الخام.

6- لدى الثركة دراسات لتلافي ومعالجة مسببات التلوث الا انهُ لايؤخذ بنظر الاعتبار تكاليفها بالنسبة الى

$$
\text { مقدار النفع و الضرر على البيئة إضافة لعدم وجود خطط در اسة سنوية. }
$$

7- نظم السلامة البيئية للشركة تتميز بخضوعها للمعايير الموضوعة لها الا انها تفتقر الى وجود اجر اءات احترازية تواجه التلوث الذي تتعرض لهُ المناطق الزر اعية لقرب الثركة منها اكثر من المناطق السكنية،

$$
\text { اضافة لافتقار ها الى وحدة معالجة الهو اءه }
$$

8- لايتم مقارنة نتائج فحوصات المواد الاولية و النفايات مع المعايير الدولية عند القيام بدر اسة الجدوى الفنية


وكذلك انبعاثات الغاز في حالة الحقن بالغاز لمكمن النفط كما هو الحال في حقل الاحدب.

9- تركزت على نقاط ضعف بعمل الثركة في مدى تحقيق منطلبات التحليل المالي للبيئة و هذا ما نر اهُ جلياً في قائمة الفحص الواردة في الجدول رقم (1) في الجانب العملي من البحث. 
المصادر:

1. الكافي، فائزة، (الرقابة المالية)، مجلة الرقابة المالية تصدرها المجموعة العربية للاجهزة العليا المالية

$$
\text { و المحاسبية، عدد (58) حزيران/2011. }
$$

2. INTOSAI, (Performance Audit), search From Wikipedia, the free encyclopedia, 2018 .

3. Thompsno,"National Land \& Water Resou sces Audit", AProgram of the Natural Heritage Trust, 2010.

4. Jak, roson, (Risk-Based Audit Plan), Audit Branch of Natural Resouces Canada (NR CAN), 2018.

5. هية، احمد يعرب عبد الكريم، (دور المدقق الخارجي في الرقابة البيئية للشركات النفطية - بحث تطبيقي

في شركة نفط الثمال / شركة عامة مقدم الى مجلس المعهد العالي للار اسات المحاسبية و المالية / جامعة بغداد و هو جزء من متطلبات نيل شهادة المحاسب القانوني، 2016.

4. اسماعيل، عامر، (نظام الايزو 14000)، المنتدى العربي للموارد البشرية / قسم علوم الادارة / ادارة الجودة الثاملة / نظام الايزو 14000،

5. أبو القز، منى فؤاد عبد الهادي، (تقييم المشروعات خلال فترة التشغيل التجريبي وفق معيار الكلفة والجودة و الوقتـ بحث تطبيقي في المديرية العامة لتوزيع كهرباء الرصافة)، الرسالة مقدمة الى مجلس كلية الادارة والاقتصاد/جامعة بغداد وهي جزء من متطلبات نيل درجة الماجستير في تقويم الاداء/قسم ادارة الاعمال، 2016.

6. بلوم،سعيد، (أساليب الرقابة ودور ها في تقييم أداء المؤسسة الاقتصادية در اسة مبدانية بمؤسسة المحركات والجرارات بالسوناكوم (SONACOME))، رسالة مكملة لنيل شهادة الماجستير في تنمية و تسبير الموارد البشرية مقدمة الى وزارة التعليم العالي والبحث العلمي /جامعة منتوري قسنطينة / كلية العلوم الإنسانية و العلوم الإجتماعية قسم علم الإجتماع و الديمغر افيا، 2016.

7. ISO 14000, Environmental Auditing principl, 2002.

8. كاظم،رحاب حسين جواد، (سلسلة جودة البيئة المواصفات القياسية 14000 ايزو)، شبكة جامعة بابل / نظام التعليم الالكتروني لقسم الادارة البيئية نشر في 2016/10/7. 
9. هاثم،زينب حموي، (قياس تكاليف الجودة البيئية و أثزه في ترشيد الاداء البيئي) الرسالة مقدمة الى مجلس كلية الادارة والاقتصاد / جامعة بغداد وهي جزء من متطلبات نيل درجة الماجستير في العلوم المحاسبية، .2016

10. (Seven ways oil and gas drilling is bad news for the Environment), http://environment-ecology.com/energy-and-environment/92-how-does-oilimpact-the-environment.html, 2018.

11. PCMH, Agency Global Resaerch and Quality, ( Resaerch Methods Series), 2007. 12. قانون تأسبس وزارة البيئة رقم (37) لسنة /2008 المنشور بجريدة الوقائع العراقية عدد (4092) في $.2008 / 10 / 20$

13. قانون حماية وتحسين البيئة رقم (27) لسنة /2011 المنشور بجريدة الوقائع العراقية عدد (4122) في

$$
\text { 2010/1/25 الفروع (6-8)و و(7-1). }
$$

14. قانون الحفاظ على الثروة الهيدروكاربونية رقم (84) لسنة/1985 المنشور بجريدة الوقائع العراقية عدد 1985/10/21. 13068) في (3)

15. النظام الداخلي لوز ارة البيئة العر اقية رقم (1) لسنة /2011 المنشور بجريدة الوقائع العراقية عدد (4211) في 2011/10/5 ص2

16. نظام الحفاظ على الموارد المائية رقم (2) لسنة/2001 المنشور بجريدة الوقائع العر اقية عدد (3890) في $.2001 / 8 / 6$

17. Department of Agriculture, (Audit Report Natural Resources Coservation), of the office of inspecctar General, 2009.

18. Hairul and other, (Sustainable Development What is the Role of Audit), Journal of Sustainability Science and management, Volume 11 Number 1, June 2016: 99-112, Institute for Environment and Development (LESTARI), University Kebangsaan Malaysia, Bangi, Selangor, 2016.

19. سماهقة يى، ايوب انور حمد، (تحليل العلاقة بين البيئة والتنمية المستدامة مع اشارة خاصة لحالة محافظة بابل) الرسالة مقدمة الى مجلس كلية الادارة والاقتصاد/جامعة بغداد وهي جزء من متطلبات نيل درجة الماجستير في العلوم الاقتصاية، 2006. 
20. مبارك، فاطمة، (التنمية المستدامة أصلها نشأتها)، مقالة نشرت في مجلة بيئة المدن الاكتروني، العدد

$$
\text { الثالث عشر - يناير/2016، دُبيـ الامارات العربية المتحدة. }
$$

21. Unesco Edncatin soctor, (Edncatin For Sustainable Development), Source Book, united, 2012.

22. البنك الدولي، (ارشادات بشان البيئة والصحة والسلامة الخاصة بالمشاريع البرية لاستخراج النفط

$$
\text { و الغاز)، } 2007 .
$$

23. سليمان،حمح محمود، (الجغرافية والبيئة)، الطبعة الاولى، مطابع الهيئة العامة السورية للكتاب، دمشق-

$$
\text { سوريا، } 2009 .
$$

24. Kourtellis," Environmental Audit-The Future Importance And Role Of Sais To Encourage This Practice", 17 Th Common wealth Auditors General Conference October 10-13-1999, Sun City-South Africa.

$$
\begin{aligned}
& \text { 25. فيشر،انطو انيس، (أقتصاديات الموارد و البيئة)، دار المريخ للنشر ، الرياض ـ المملكة العربية السعودية، } \\
& .2002 \\
& \text { 26. سالم وعبد المنعم، ابو بكر الصديق، نبيل محمود، (التلوث سلسة الاسس التكنولوجي المصضلة و الحل)،دار } \\
& \text { النشر مركز الكتب الثقافية، بيروتـ لبنان الطبعة الاولى، } 1989 . \\
& \text { 27. السعدي،حسين علي، (اساسيات علم البيئة والتلوث)، دار البازوري العلمية للنشر والتوزيع، عمان- }
\end{aligned}
$$

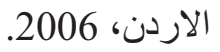

$$
\begin{aligned}
& \text { 28. التميمي، كامل مهدي، (مبادئ التلوث البيئي)، الاهلية للنشر و التوزيع، عمان- الاردن، } 2004 .
\end{aligned}
$$

29. NATIONS UNIES, (International expert group meeting on indigenous peoples and protection of the environment), The Adverse Impacts of Oil Pollution on the Environment and Wellbeing of a Local Indigenous Community: The Experience of the Ogoni People of Nigeria, 2007.

$$
\begin{aligned}
& \text { 30. دعبس، يسرى، (تلوث البيئة وتحديات البقاء رؤية أنثربولوجية)، علم الانسان وقضايا المجتمع الكتاب } \\
& \text { الخامس عشر، حقوق الطبع محفوظة للمؤلف، } 1999 .
\end{aligned}
$$


31. الساعدي وآخرون، زيدون خلف، خليل ابراهيم، (مشروع معالجة الماء المصاحب في شركة نفط

$$
\text { الجنوب)، بحث من اعداد مجموعة من موظفي مركز البحث والتطوير النفطي. }
$$

32. الحلفي، عبد الجبار عبود، (تقنيات الاستخلاص النفطي المدعم إثارة الى تجارب اربع دول)، مجلة الخليج

$$
\text { العربي، مجلد (38) العدد (3-4) لسنة /2010. }
$$

33. NATIONS UNIES (How Does Oil Impact the Environment) http://environmentecology.com/energy-and-environment/92-how-does-oil-impact-theenvironment.html, 2018.

$$
\begin{aligned}
& \text { 34. جمهورية العراق / الامانة العامة لمجلس الوزراء / دائرة شؤون مجلس الوزراء المرقم } \\
& \text { (ش.ز/12865/4/1/10) في 2010/4/15 و الخاص بتأسيس (شركة نفط الوسط شركة عامة) بموجب } \\
& \text { القرار المرقم (155) لسنة / 2010 في 2010/4/14. }
\end{aligned}
$$

